\title{
APPLICATION OF EDAS, MARCOS, TOPSIS, MOORA AND PIV METHODS FOR MULTI-CRITERIA DECISION MAKING IN MILLING PROCESS
}

\author{
DO Duc Trung ${ }^{1}$ \\ ${ }^{1}$ Faculty of mechanical engineering, Hanoi University of Industry, Hanoi-100000, Vietnam, \\ e-mail: doductrung@haui.edu.vn
}

\begin{abstract}
Low surface roughness and high Material Removal Rate $(M R R)$ are expected in most machining methods in general and milling method in particular. However, they sometimes do not occur, for example, the $M R R$ is often small as the surface roughness is low. In this case, the decisions made should ensure that desires are simultaneously satisfied. This situation leads to a problem known as multi-criteria decision making ( $M C D M)$. In this study, five methods including EDAS, MARCOS, PIV, MOORA and TOPSIS are used together for the decision-making in the milling process. The purpose of the research is to determine the value of cutting parameters for both the low surface roughness and large $M R R$. The comparison of these methods for finding the best is carefully discussed as well.
\end{abstract}

KEYWORDS: EDAS, MARCOS, PIV, MOORA, TOPSIS

\section{Abbreviations}

MCDM: Multi-Criteria Decision Making

MRR: Material Removal Rate

$S A W$ : Simple additive weighting.

WASPAS: Weighted aggregates sum product assessment.

TOPSIS: Technique for Order of Preference by Similarity to Ideal Solution

VIKOR: Vlsekriterijumska optimizacija i kompromisno resenje in Serbian.

MOORA: Multiobjective optimization on the basis of ratio analysis.

COPRAS: Complex proportional assessment.

$P I V$ : Proximity indexed value.

PSI: Preference selection index.

$E D A S$ : Evaluation based on distance from average solution

MARCOS: Measurement alternatives and ranking according to compromise solution

CODAS: Combinative distance based assessment

WASPAS: Weighted Aggregated Sum Product Assessment

WPAS: Weighted Product Assessment 


\section{Introduction}

Milling is considered to be the most productive of machining methods, especially in the case of using a face milling cutter where its teeth are involved in the cutting process [1]. This method is commonly used for machining mechanical products, hence, research of seeking solutions in order to improve the quality of machined surface and machining efficiency is increasingly paid attention. One of the research directions primarily concerned is finding a solution to reach the low surface roughness and large $M R R$. Surface roughness directly affects workability and service life of the product, and $M R R$ is the most important measure to evaluate the productivity of the machining process [2]. In fact, however, these requirements are sometimes not achieved simultaneously [3]. Several studies also point that out. In an experiment including nine trials of milling Ti-6Al-4V alloy, the trial with the highest $M R R$ had the higest surface roughness [4]. The results of twenty-seven SCM440 steel milling experiments show that the lowest surface roughness and $M R R$ were in the same test [5]. As nine 060A4 steel milling tests were performed, the one with the lowest surface roughness also had the small MRR [6]. Upon implementing twenty experiments for milling SKD11 steel, the test with the lowest surface roughness nearly had the minimum MRR [7], etc. Under these circumstances, it is necessary to define an experiment where the surface roughness is considered "minimum" and the $M R R$ is considered "maximum". This is called "multi-criteria decision making" [4-7].

Evaluation based on Distance from Average Solution $(E D A S)$ is a multi-criteria decision making method introduced for the first time in 2015 [8]. It has been applied in several studies. The EDAS method was applied to multi-criteria decision making for robot selection by considering four parameters including: load capacity, repeatability error, vertical reach, and degrees of freedom $[9,10]$. The EDAS method was also applied to multi-criteria decision making for material handling equipment [10]. Besides the EDAS, authors of these papers used four other methods (including CODAS, MOORA, WASPAS and TOPSIS) to solve the same problem. The results demonstrated that all five methods identified the best solution. The multi-criteria decision-making for choosing a green supplier to obtain objectives given by taking account of four factors including cost, quality, environment and delivery time was also carried out using the EDAS [12]. Some researchers [13] applied the EDAS to make a decision about selecting a smartphone that meets the criteria of cost and necessary features for users' needs. The EDAS was also used [14] to make multi-criteria decisions for seeking a diesel engine. Besides the method, authors also applied five other methods (including MOORA, WSPAS, TOPSIS, WASPAS, and VIKOR) to select a best alternative. The results revealed that: except for the TOPSIS method, the other five (including EDAS, MOORA, WPAS, WASPAS, and VIKOR) all pointed out the same best solution. The EDAS is also used to decide the percentage of additives in the process of making composite materials (Titanium Di-Oxide Filled Woven Glass Fibre Reinforced Polymer Composites). The purpose of this study is to make a composite material that simultaneously obtains the desired tensile strength, compressive strength, adhesion strength and impact strength [15]. The EDAS method was applied to rank in the insurance industry of twenty-seven OECD countries (Organization for Economic Cooperation and Development) [16]. The use of EDAS method was effective to provide solutions for reducing carbon emissions into the environment [17], choosing the type of wireless sensor network [18], and selecting sewing machines for the textile factory [19]; etc.

It can be seen that the EDAS method is used to make multi-criteria decisions in different fields. However, there is likely no application of the EDAS method for multi-criteria-decision making in the machining process in general and milling process in particular. 
Measurement Alternatives and Ranking according to Compromise Solution (MARCOS) is another multi-criteria decision making method introduced for the first time in 2020 [20]. Although it has only been published for a short time, this method has been applied to multicriteria decision making in a number of studies such as: determining intermediate modes of transport between countries in the Danube region [21], reducing risks in road traffic [22], choosing cargo handling equipment for small warehouses [23], recruiting employees for a transportation company [24], identifying construction cost [25]. However, it appears that there are no studies on application of the MARCOS method to multi-criteria decision making in the machining process in general and milling process in particular.

Among the multi-criteria decision-making methods, TOPSIS is the most used method in many different fields $[13,26]$. In a recent study, eight multi-criteria decision-making methods were compared for $150 \mathrm{Cr} 14$ steel turning operation [27]. Its researchers used eight methods at the same time, including SAW, WASPAS, TOPSIS, VIKOR, MOORA, COPRAS, PIV, and PSI. The study concluded that seven of the methods identified the same solution (with the exception of the PSI method). However, during making a multi-criteria decision on the steel machining process of ASTM A588, it was shown that the TOPSIS method did not determine the best option compared to the MOORA method [28], and in the process of making a multicriteria decision on the $9 \mathrm{XC}$ steel machining operation, it was also revealed that the TOPSIS method did not define the best alternative compared to PIV [29]. Thus, even though the TOPSIS is mostly used, there are probably other methods to be more effective than it under certain circumstances.

In this study, a multi-criteria decision on the milling process is made using all the five methods, including EDAS, MARCOS, PIV, MOORA và TOPSIS. There are two reasons for this choice: First, as mentioned, the EDAS and MARCOS are applied for multi-criteria decision making in various fields, but neither of them has ever been used for multi-criteria decision-making of the milling process; Second, TOPSIS is the most used method in multicriteria decision making, but some studies indicated the PIV and MOORA are more effective than the TOPSIS. Consequently, all five methods may provide a useful comparison.

\section{Several methods of multi-criteria decision making}

\subsection{EDAS method}

The steps for implementation of multi-criteria decision making according to the EDAS method are as follows [8].

Step 1: Building a decision matrix based on the following formula:

$$
X=\left[x_{i j}\right]_{m \times n}=\left[\begin{array}{ccc}
x_{11} & \cdots & x_{1 n} \\
x_{21} & \cdots & x_{2 n} \\
\vdots & \cdots & \vdots \\
x_{m n} & \cdots & x_{m n}
\end{array}\right]
$$

Where: $m$ is the number of options, $n$ is the number of criteria, $x_{i j}$ is the value of criterion $j$ at option $i$.

Step 2: Determining an average $(A V G)$ of the options.

$$
A V G=\frac{\sum_{i=1}^{m} x_{i}}{m}
$$

Step 3: Defining positive distance $(P D)$ and negative distances $(N D)$ from an average 


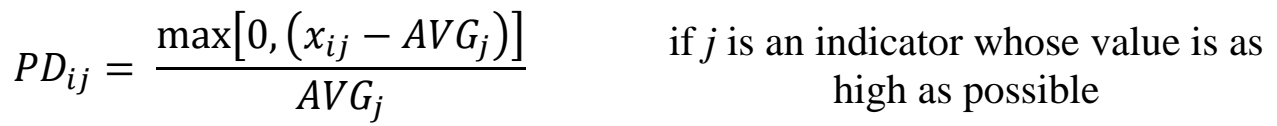

$$
\begin{aligned}
& P D_{i j}=\frac{\max \left[0,\left(A V G_{j}-x_{i j}\right)\right]}{A V G_{j}} \quad \text { if } j \text { is an indicator whose value is as } \\
& N D_{i j}=\frac{\max \left[0,\left(A V G_{j}-x_{i j}\right)\right]}{A V G_{j}} \quad \text { if } j \text { is an indicator whose value is as } \\
& N D_{i j}=\frac{\max \left[0,\left(x_{i j}-A V G_{j}\right)\right]}{A V G_{j}} \quad \text { if } j \text { is an indicator whose value is as }
\end{aligned}
$$

Step 4: Calculating the sum of positive distances (SoP) and the sum of negative distances (SoN).

$$
\begin{aligned}
& \operatorname{SoP}_{i}=\sum_{i=1}^{m} w_{j} \cdot P D_{i j} \\
& \operatorname{SoN}_{i}=\sum_{i=1}^{m} w_{j} \cdot N D_{i j}
\end{aligned}
$$

where $w_{j}$ is the weight of the criterion $j$.

Step 5: Normalizing the SoP and SoN values according to the formula.

$$
\begin{gathered}
S S o P_{i}=\frac{\operatorname{SoP}_{i}}{\max \left(\operatorname{SoP}_{i}\right)} \\
\operatorname{SSoN}_{i}=1-\frac{\operatorname{SoN}_{i}}{\max \left(\operatorname{SoN}_{i}\right)}
\end{gathered}
$$

Step 6: Calculating appraisement score (APS) of the options based on the formula.

$$
A P S_{i}=\frac{1}{2}\left(S_{S o P}+S_{S o N}\right)
$$

Step 7: Ranking the options according to the rule that the option with the highest $A P S_{i}$ is considered the best.

\subsection{MARCOS method}

The steps for implementation of multi-criteria decision making according to the MARCOS method are as follows [20]:

Step 1: Similar to step 1 of the EDAS method.

Step 2: Building an expanded matrix by adding an ideal solution $(A I)$ and the opposite solution to the ideal solution $(A A I)$.

$$
X=\begin{gathered}
A A I \\
A_{1} \\
A_{2} \\
\vdots \\
A_{m} \\
A I
\end{gathered}\left[\begin{array}{ccc}
x_{a a 1} & \cdots & x_{a a n} \\
x_{11} & \cdots & x_{1 n} \\
x_{21} & \cdots & x_{2 n} \\
\vdots & \vdots & \vdots \\
x_{m 1} & \cdots & x_{m n} \\
x_{a i 1} & \cdots & x_{a i n}
\end{array}\right]
$$

where:

$A A I=\min \left(x_{i j}\right) ; i=1,2, \ldots, m ; j=1,2, \ldots, n$ if $j$ is an indicator whose value is as high as possible 
$A A I=\max \left(x_{i j}\right) ; i=1,2, \ldots, m ; j=1,2, \ldots, n$ if $j$ is an indicator whose value is as low as possible

$A I=\max \left(x_{i j}\right) ; i=1,2, \ldots, m ; j=1,2, \ldots, n$ if $j$ is an indicator whose value is as high as possible

$A I=\min \left(x_{i j}\right) ; i=1,2, \ldots, m ; j=1,2, \ldots, n$ if $j$ is an indicator whose value is as low as possible

Step 3: Normalizing the expanded matrix according to the formula:

$$
\begin{array}{cc}
n_{i j}=\frac{x_{A I}}{x_{i j}} & \begin{array}{c}
\text { if } j \text { is an indicator whose value is as } \\
\text { low as possible }
\end{array} \\
n_{i j}=\frac{x_{i j}}{x_{A I}} & \text { if } j \text { is an indicator whose value is as } \\
\text { high as possible }
\end{array}
$$

Step 4: Building a normalized matrix taking into account the weights of the parameters with the normalized value calculated according to the formula.

$$
v_{i j}=n_{i j} \cdot w_{j}
$$

where, $w_{j}$ is the weight of the criterion $j$.

Step 5: Calculating the coefficients $K_{i}^{+}$and $K_{i}^{-}$according to the formula:

$$
\begin{aligned}
K_{i}^{-} & =\frac{S_{i}}{S_{A A I}} \\
K_{i}^{+} & =\frac{S_{i}}{S_{A I}}
\end{aligned}
$$

where:

$S_{i}, S_{A A I}$ and $S_{A I}$ are the sum of the values of $v_{i j}, x_{a a i}$ and $x_{a i}$, respectively, where $i=1,2, \ldots, m$.

Step 6: Calculating $f\left(K_{i}^{+}\right)$and $f\left(K_{i}^{-}\right)$according to the formula:

$$
\begin{aligned}
& f\left(K_{i}^{-}\right)=\frac{K_{i}^{+}}{K_{i}^{+}+K_{i}^{i}} \\
& f\left(K_{i}^{+}\right)=\frac{K_{i}^{-}}{K_{i}^{+}+K_{i}^{i}}
\end{aligned}
$$

Step 7: Calculating $f(K i)$ according to the following formula and rank the options.

$$
f\left(K_{i}\right)=\frac{K_{i}^{+}+K_{i}^{-}}{1+\frac{1-f\left(K_{i}^{+}\right)}{f\left(K_{i}^{+}\right)}+\frac{1-f\left(K_{i}^{-}\right)}{f\left(K_{i}^{-}\right)}}
$$

Ranking is based on the rule that the option with the highest value of the $f(K i)$ is considered the best.

\subsection{PIV method}

The steps for implementation of multi-criteria decision making according to the PIV method are as follows [30]:

Step 1: Similar to step 1 of the EDAS method.

Step 2: Calculating the conversion values. 


$$
x_{i j}^{\prime}=\frac{x_{i j}}{\sqrt{\sum_{i=1}^{n} x_{i j}^{2}}}
$$

Step 3: Calculating the normalized value according to the formula.

$$
X=w_{j} \cdot x_{i j}^{\prime}
$$

where, $w_{j}$ is the weight of the criterion $j$.

Step 4: Calculating weighted proximity index

$$
u_{i}= \begin{cases}X_{\max }-X_{i} & \text { for } C_{1}, C_{2}, \ldots, C_{n} \in B \\ X_{i}-X_{\min } & \text { for } C_{1}, C_{2}, \ldots, C_{n} \in C\end{cases}
$$

where $B$ represents the criterion whose value is as high as possible, and $C$ represents the criterion whose value is as low as possible.

Step 5: Determining the overall proximity value according to the following formula.

$$
d_{i}=\sum_{j=1}^{n} u_{i}
$$

Step 6: Ranking the options according to the rule that the option with the highest of $d_{i}$ is considered the best.

\subsection{MOORA method}

The steps for implementation of multi-criteria decision making according to the MOORA method are as follows [31]:

Step 1: Similar to step 1 of the EDAS method.

Step 2: Calculating the normalized decision matrix $\left[X_{i j}\right]_{m \times n}$ based on the formula.

$$
K=\left[X_{i j}\right]_{m \times n} \quad K_{i j}=\frac{x_{i j}}{\sqrt{\sum_{i=1}^{m} x_{i j}^{2}}}
$$

Step 3: Calculating the decision matrices after normalizing the weights based on the formula.

$$
W_{i j}=w_{j} \times k_{i j}
$$

Step 4: Defining $P_{i}$ and $R_{i}$ based on the following formulas.

$$
\begin{gathered}
P_{i}=\frac{1}{|B|} \sum_{j \in B} W_{i j} \\
R_{i}=\frac{1}{|N B|} \sum_{j \in N B} W_{i j}
\end{gathered}
$$

where $B$ represents the criterion whose value is as high as possible, and $N B$ represents the criterion whose value is as low as possible.

Step 5: Identifying $Q_{i}$ based on the following formula.

$$
Q_{i}=P_{i}-R_{i}
$$

\subsection{TOPSIS method}

The steps for implementation of multi-criteria decision making according to the TOPSIS method are as follows [32]: 
Step 1: Similar to step 1 of the EDAS method.

Step 2, step 3: Similar to step 2 and 3 of the MOORA method.

Step 4: Determining the best solution $A^{+}$and the worst solution $A^{-}$for the criteria according to the following formulas.

$$
\begin{aligned}
A^{+} & =\left\{k_{1}^{+}, k, \ldots, k_{j}^{+}, \ldots, k_{n}^{+}\right\} \\
A^{-} & =\left\{k_{1}^{-}, k_{2}^{-}, \ldots, k_{j}^{-}, \ldots, k_{n}^{-}\right\}
\end{aligned}
$$

where: $k_{j}^{+}$and $k_{j}^{-}$are the best and worst values of criterion $j$, respectively.

Step 5: Identifying $S_{i}^{+}$and $S_{i}^{-}$based on the following formulas.

$$
\begin{array}{cc}
S_{i}^{+}=\sqrt{\sum_{j=1}^{n}\left(k_{i j}-k_{j}^{+}\right)^{2}} & \mathrm{i}=1,2, \ldots, \mathrm{m} \\
S_{i}^{-}=\sqrt{\sum_{j=1}^{n}\left(k_{i j}-k_{j}^{-}\right)^{2}} & \mathrm{i}=1,2, \ldots, \mathrm{m}
\end{array}
$$

Step 6: Defining $C_{i}^{*}$ and based on the following formulas.

$$
C_{i}^{*}=\frac{s_{i}^{-}}{s_{i}^{+}+s_{i}^{-}} \quad \mathrm{i}=1,2, \ldots, \mathrm{m} ; 0 \leq C_{i}^{*} \leq 1
$$

Step 7: Ranking the options according to the rule that the option with the highest $C_{i}^{*}$ is considered the best.

\section{Experiment of milling operation}

SB410 steel (conforming to JIS - Japanese standard) was used in the experiments. The results of spectral analysis determined the chemical composition of steel as shown in Table 1. This steel has good machinability, low cost and is the most popular steel for manufacturing common mechanine parts made of silver, shafts, gears, levers.

Table 1. Chemical composition of SB410 steel

\begin{tabular}{|c|c|c|c|c|c|c|c|c|c|}
\hline \multicolumn{10}{|c|}{ Composition (\%) } \\
\hline$C$ & $S i$ & $M n$ & $C r$ & $N i$ & $M o$ & $V$ & $T i$ & $B$ & $C u$ \\
\hline 0.44 & 0.25 & 0.63 & 0.24 & 0.11 & 0.04 & 0.02 & 0.002 & 0.0006 & 0.23 \\
\hline
\end{tabular}

A JLVH320B vertical milling machine was used to perform the experiments. Due to the use of a hydraulic motor for controlling feed, feed rate can be adjusted at any level. The determination of the feed rate is made by timing. The cutting tool moves by $0,02 \mathrm{~mm}$ for each mark on the vertical vernier of the machine, based on which the depth of cut is adjusted. The control of the spindle speed of the machine is done through the lever system, which includes twenty-four spindle speed levels.

The cutting tool used in this study is made of a hard alloy, coated with TiN. Its type is widely used in milling due to a relatively high heat resistance and good cutting performance [33]. The cutting tool holder has a diameter of $82 \mathrm{~mm}$.

The spindle speed, feed rate and depth of cut are selected as the input parameters for experiments. These three parameters can all be quickly adjusted by the machine operator and are also selected as experimental input parameters in many studies [34]. Their values are chosen based on the author's experience in production during milling SB410 steel as well as in accordance with the ability of the testing machine. The values of cutting parameters are presented in Table 2. 
Table 2. Cutting parameters

\begin{tabular}{|l|c|c|c|c|c|}
\hline \multirow{2}{*}{ Parameter } & \multirow{2}{*}{ Symbol } & \multirow{2}{*}{ Unit } & \multicolumn{3}{c|}{ Value at level } \\
\cline { 4 - 6 } & & & 1 & 2 & 3 \\
\hline Spindle speed & $n$ & $\mathrm{rev} / \mathrm{min}$ & 70 & 105 & 126 \\
\hline Feed rate & $f$ & $\mathrm{~mm} / \mathrm{min}$ & 538 & 788 & 1152 \\
\hline Depth of cut & $a_{p}$ & $\mathrm{~mm}$ & 0.4 & 0.6 & 0.8 \\
\hline
\end{tabular}

Taguchi method is applied to design a matrix experiment. This method has more advantages than other experimental matrix design methods, namely: the number of experiments is minimum, the input parameters are possibly both quantitative and qualitative, the values of the input parameters do not need to comply with the rule of average $[35,36]$. In this case, for example, the level number of spindle speeds of the milling machine is finite, its value encoded at level 2 which is supposed to be the average of the values encoded at level 1 and 3 (ex: $105 \neq(70+126) / 2$ ) is not appropriate. Hence, the Taguchi is the most suitable to design the experimental matrix. With three input parameters and three values for each of them, the experimental matrix is designed as an orthogonal array, including nine trials as shown in Table 3.

Table 3. Orthogonal array $L 9$ and result

\begin{tabular}{|c|c|c|c|c|c|c|c|c|}
\hline \multirow{2}{*}{ No. } & \multicolumn{3}{|c|}{ Code value } & \multicolumn{3}{c|}{ Actual value } & \multicolumn{2}{c|}{ Response } \\
\cline { 2 - 9 } & $n$ & $f$ & $a_{p}$ & $\begin{array}{c}n \\
(\mathrm{rev} / \mathrm{min})\end{array}$ & $\begin{array}{c}f \\
(\mathrm{~mm} / \mathrm{min})\end{array}$ & $\begin{array}{c}a_{p} \\
(\mathrm{~mm})\end{array}$ & $\begin{array}{c}R_{a} \\
(\mu \mathrm{m})\end{array}$ & $\begin{array}{c}\text { MRR } \\
\left(\mathrm{mm}^{3} / \mathrm{min}\right)\end{array}$ \\
\hline$A 1$ & 1 & 1 & 1 & 538 & 70 & 0.4 & 0.571 & 1120 \\
\hline$A 2$ & 1 & 2 & 2 & 538 & 100 & 0.6 & 0.818 & 2400 \\
\hline$A 3$ & 1 & 3 & 3 & 538 & 130 & 0.8 & 0.493 & 4160 \\
\hline$A 4$ & 2 & 1 & 2 & 788 & 70 & 0.6 & 0.426 & 1680 \\
\hline$A 5$ & 2 & 2 & 3 & 788 & 100 & 0.8 & 0.470 & 3200 \\
\hline$A 6$ & 2 & 3 & 1 & 788 & 130 & 0.4 & 0.851 & 2080 \\
\hline$A 7$ & 3 & 1 & 3 & 1152 & 70 & 0.8 & 0.437 & 2240 \\
\hline$A 8$ & 3 & 2 & 1 & 1152 & 100 & 0.4 & 0.694 & 1600 \\
\hline$A 9$ & 3 & 3 & 2 & 1152 & 130 & 0.6 & 0.717 & 3120 \\
\hline
\end{tabular}

In order to reduce random errors during the experiment, the surface roughness was measured at least three times for each specimen, the roughness value at each experiment was the average of measurements. Due to calculation based on formula (35), MRR is not affected by the random errors. Where $f, a_{p}, b_{w}$ are feed rate, depth of cut and width of cut, respectively. Since the milling cutter diameter is $82 \mathrm{~mm}$ and the width of the workpiece is $40 \mathrm{~mm}$, it is possible to cut the workpiece with one pass. Therefore, the width of cut is equal to the width of the workpiece, $b_{w}=40 \mathrm{~mm}$.

$$
M R R=f \cdot a_{p} . b_{w}\left(\mathrm{~mm}^{3} / \mathrm{min}\right)
$$

The tests were performed in the order shown in Table 3, the surface roughness and MRR were included in this table as well.

In Table 3, the minimum surface roughness is $0.426(\mu \mathrm{m})$ at $A 4$, while the maximum $M R R$ is $4160(\mathrm{~mm} 3 / \mathrm{min})$ at $A 3$. Thus, it is clear that there is no solution that has the minimum surface roughness and the maximum $M R R$ simultaneously. It is only possible to define an alternative where the surface roughness is considered to be "lowest" and the MRR is considered to be "highest" if multi-criteria decision making is applied. 


\section{$4 \quad$ Multi-criteria decision making}

\subsection{Determination of the weights for the criteria}

In this study, the weights of the criteria were determined by the Entropy weight method. The Entropy method is recommended to use for comparison of multi-criteria decision-making methods [27]. It is introduced in many papers [27, 37]. The weights of surface roughness and MRR calculated are 0.6641 and 0.3359 , respectively.

\subsection{Application of EDAS method}

The decision matrix is the last two columns on the right of the experimental result table (table 3).

The average values of surface roughness and $M R R$ are correspondingly defined are 0.609 $(\mu \mathrm{m})$ và $2400\left(\mathrm{~mm}^{3} / \mathrm{min}\right)$ based on formula $(2)$.

The $P D_{i j}$ and $N D_{i j}$ values of surface roughness and $M R R$ are determined based on formula (3), (4), (5) and (6), as shown in Table 4.

Table 4. $P D_{i j}$ and $N D_{i j}$ of surface roughness and $M R R$

\begin{tabular}{|c|c|c|c|c|}
\hline \multirow{2}{*}{ No. } & \multicolumn{2}{|c|}{$P D i j$} & \multicolumn{2}{c|}{$N D_{i j}$} \\
\cline { 2 - 5 } & $R a$ & $M R R$ & $R a$ & $M R R$ \\
\hline$A 1$ & 0.0617 & 0.0000 & 0.0000 & 1.1429 \\
\hline$A 2$ & 0.0000 & 0.0000 & 0.3442 & 0.0000 \\
\hline$A 3$ & 0.1899 & 0.7333 & 0.0000 & 0.0000 \\
\hline$A 4$ & 0.3000 & 0.0000 & 0.0000 & 0.4286 \\
\hline$A 5$ & 0.2277 & 0.3333 & 0.0000 & 0.0000 \\
\hline$A 6$ & 0.0000 & 0.0000 & 0.3984 & 0.1538 \\
\hline$A 7$ & 0.2819 & 0.0000 & 0.0000 & 0.0714 \\
\hline$A 8$ & 0.0000 & 0.0000 & 0.1404 & 0.5000 \\
\hline$A 9$ & 0.0000 & 0.3000 & 0.1782 & 0.0000 \\
\hline
\end{tabular}

The value of $\mathrm{SoP}_{i}, \mathrm{SoN}_{i}, \mathrm{SSoP}_{i}, \mathrm{SSoN}_{i}, \mathrm{APS}_{i}$ as shown in Table 5 is determined by formula (7), (8), (9), (10), (11). The ranking results of the options are also presented in this table.

Table 5. Some parameters in EDAS

\begin{tabular}{|c|c|c|c|c|c|c|}
\hline No. & SoP $_{i}$ & SoN $_{i}$ & SSoP $_{i}$ & SSoN $_{i}$ & $A P S_{i}$ & Rank \\
\hline$A 1$ & 0.0410 & 0.3839 & 0.1100 & 0.0000 & 0.0550 & 9 \\
\hline$A 2$ & 0.0000 & 0.2285 & 0.0000 & 0.4047 & 0.2023 & 6 \\
\hline$A 3$ & 0.3724 & 0.0000 & 1.0000 & 1.0000 & 1.0000 & 1 \\
\hline$A 4$ & 0.1992 & 0.1440 & 0.5349 & 0.6250 & 0.5799 & 4 \\
\hline$A 5$ & 0.2632 & 0.0000 & 0.7066 & 1.0000 & 0.8533 & 2 \\
\hline$A 6$ & 0.0000 & 0.3162 & 0.0000 & 0.1763 & 0.0881 & 8 \\
\hline$A 7$ & 0.1872 & 0.0240 & 0.5026 & 0.9375 & 0.7201 & 3 \\
\hline$A 8$ & 0.0000 & 0.2612 & 0.0000 & 0.3196 & 0.1598 & 7 \\
\hline$A 9$ & 0.1008 & 0.1183 & 0.2706 & 0.6918 & 0.4812 & 5 \\
\hline
\end{tabular}




\subsection{Application of MARCOS method}

Formula (12) is applied to identify the $A I$ of surface roughness and MRR correspondingly are $0.426(\mu \mathrm{m}), 4160\left(\mathrm{~mm}^{3} / \mathrm{min}\right) ; A A I$ of surface roughness and MRR correspondingly are $0.851(\mu \mathrm{m}), 1120\left(\mathrm{~mm}^{3} / \mathrm{min}\right)$.

Formulas (13) to (20) are used to define the parameters of $n_{i j}, v_{i j}, K_{i}^{-}, K_{i}^{+}, f\left(K_{i}^{-}\right), f\left(K_{i}^{+}\right)$and $f\left(K_{i}\right)$ as shown in Table 6 . The ranking results of the options are also presented in this table.

Table 6. Some parameters in MARCOS

\begin{tabular}{|c|c|c|c|c|c|c|c|c|}
\hline \multirow{2}{*}{ No. } & \multicolumn{2}{|c|}{$n_{i j}$} & \multicolumn{2}{c|}{$v_{i j}$} & \multirow{2}{*}{$K_{i}^{-}$} & \multirow{2}{*}{$K_{i}^{+}$} & \multirow{2}{*}{$f\left(K_{i}\right)$} & \multirow{2}{*}{ Rank } \\
\cline { 2 - 8 } & $R a$ & $M R R$ & $R a$ & $M R R$ & & 0.00014 & 0.000133 & 6 \\
\hline$A 1$ & 0.7461 & 0.2692 & 0.4954 & 0.0904 & 0.00052 & 0.00014 & 7 \\
\hline$A 2$ & 0.5208 & 0.5769 & 0.3458 & 0.1938 & 0.00048 & 0.00013 & 0.000123 & 1 \\
\hline$A 3$ & 0.8641 & 1.0000 & 0.5738 & 0.3359 & 0.00081 & 0.00022 & 0.000207 & 4 \\
\hline$A 4$ & 1.0000 & 0.4038 & 0.6641 & 0.1357 & 0.00071 & 0.00019 & 0.000182 & 4 \\
\hline$A 5$ & 0.9064 & 0.7692 & 0.6019 & 0.2584 & 0.00077 & 0.00021 & 0.000196 & 2 \\
\hline$A 6$ & 0.5006 & 0.5000 & 0.3324 & 0.1680 & 0.00045 & 0.00012 & 0.000114 & 9 \\
\hline$A 7$ & 0.9748 & 0.5385 & 0.6474 & 0.1809 & 0.00074 & 0.00020 & 0.000188 & 3 \\
\hline$A 8$ & 0.6138 & 0.3846 & 0.4076 & 0.1292 & 0.00048 & 0.00013 & 0.000122 & 8 \\
\hline$A 9$ & 0.5941 & 0.7500 & 0.3946 & 0.2519 & 0.00058 & 0.00016 & 0.000147 & 5 \\
\hline
\end{tabular}

\subsection{Application of PIV method}

Formulas (21) to (24) are applied to calculate the values in the PIV method, the results are presented in Table 7. The ranking results of the options are also presented in this table.

Table 7. Some parameters in PIV

\begin{tabular}{|c|c|c|c|c|c|c|c|c|}
\hline \multirow{2}{*}{ No. } & \multicolumn{2}{|c|}{$x_{i j}^{\prime}$} & \multicolumn{2}{c|}{$X=w_{j} \cdot x_{i j}^{\prime}$} & \multicolumn{2}{|c|}{$u_{i}$} & \multirow{2}{*}{$d_{i}$} & \multirow{2}{*}{ Rank } \\
\cline { 2 - 9 } & $R a$ & $M R R$ & $R a$ & $M R R$ & $R a$ & $M R R$ & & \\
\hline$A 1$ & 0.30299 & 0.14579 & 0.2012 & 0.0490 & 0.0511 & 0.1329 & 0.1840 & 6 \\
\hline$A 2$ & 0.43406 & 0.31240 & 0.2882 & 0.1049 & 0.1381 & 0.0770 & 0.2151 & 8 \\
\hline$A 3$ & 0.26160 & 0.54149 & 0.1737 & 0.1819 & 0.0236 & 0.0000 & 0.0236 & 1 \\
\hline$A 4$ & 0.22605 & 0.21868 & 0.1501 & 0.0735 & 0.0000 & 0.1084 & 0.1084 & 4 \\
\hline$A 5$ & 0.24940 & 0.41653 & 0.1656 & 0.1399 & 0.0155 & 0.0420 & 0.0575 & 2 \\
\hline$A 6$ & 0.45157 & 0.27075 & 0.2999 & 0.0910 & 0.1498 & 0.0910 & 0.2407 & 9 \\
\hline$A 7$ & 0.23189 & 0.29157 & 0.1540 & 0.0979 & 0.0039 & 0.0840 & 0.0878 & 3 \\
\hline$A 8$ & 0.36826 & 0.20827 & 0.2445 & 0.0700 & 0.0944 & 0.1119 & 0.2064 & 7 \\
\hline$A 9$ & 0.38046 & 0.40612 & 0.2527 & 0.1364 & 0.1025 & 0.0455 & 0.1480 & 5 \\
\hline
\end{tabular}

\subsection{Application of MOORA method}

Formulas (25) to (29) are used to calculate the values in the MOORA method, the results are presented in Table 8 . The ranking results of the options are also presented in this table. 
Table 8. Some parameters in MOORA

\begin{tabular}{|c|c|c|c|c|c|c|c|c|}
\hline \multirow{2}{*}{ No. } & \multicolumn{2}{|c|}{$K_{i j}$} & \multicolumn{2}{c|}{$W_{i j}$} & \multirow{2}{*}{$P_{i}$} & \multirow{2}{*}{$R_{i}$} & $Q_{i}$ & \multirow{2}{*}{ Rank } \\
\cline { 2 - 5 } & $R a$ & $M R R$ & $R a$ & $M R R$ & & & & \\
\hline$A 1$ & 0.3030 & 0.1458 & 0.2012 & 0.0490 & 0.0490 & 0.2012 & -0.1522 & 6 \\
\hline$A 2$ & 0.4341 & 0.3124 & 0.2882 & 0.1049 & 0.1049 & 0.2882 & -0.1833 & 8 \\
\hline$A 3$ & 0.2616 & 0.5415 & 0.1737 & 0.1819 & 0.1819 & 0.1737 & 0.0082 & 1 \\
\hline$A 4$ & 0.2261 & 0.2187 & 0.1501 & 0.0735 & 0.0735 & 0.1501 & -0.0767 & 4 \\
\hline$A 5$ & 0.2494 & 0.4165 & 0.1656 & 0.1399 & 0.1399 & 0.1656 & -0.0257 & 2 \\
\hline$A 6$ & 0.4516 & 0.2707 & 0.2999 & 0.0910 & 0.0910 & 0.2999 & -0.2089 & 9 \\
\hline$A 7$ & 0.2319 & 0.2916 & 0.1540 & 0.0979 & 0.0979 & 0.1540 & -0.0560 & 3 \\
\hline$A 8$ & 0.3683 & 0.2083 & 0.2445 & 0.0700 & 0.0700 & 0.2445 & -0.1746 & 7 \\
\hline$A 9$ & 0.3805 & 0.4061 & 0.2527 & 0.1364 & 0.1364 & 0.2527 & -0.1162 & 5 \\
\hline
\end{tabular}

\subsection{Application of TOPSIS method}

Formulas (30) to (34) are applied to define the values in the TOPSIS method, the results are presented in Table 9. The ranking results of the options are included in this table as well.

Table 9. Some parameters in TOPSIS

\begin{tabular}{|c|c|c|c|c|}
\hline No. & $S_{i}{ }^{+}$ & $S_{i}{ }^{-}$ & $C_{i}{ }^{*}$ & Rank \\
\hline$A 1$ & 0.1424 & 0.0987 & 0.4093 & 6 \\
\hline$A 2$ & 0.1581 & 0.0572 & 0.2655 & 8 \\
\hline$A 3$ & 0.0236 & 0.1833 & 0.8859 & 1 \\
\hline$A 4$ & 0.1084 & 0.1517 & 0.5832 & 4 \\
\hline$A 5$ & 0.0447 & 0.1622 & 0.7837 & 2 \\
\hline$A 6$ & 0.1752 & 0.0420 & 0.1933 & 9 \\
\hline$A 7$ & 0.0840 & 0.1539 & 0.6468 & 3 \\
\hline$A 8$ & 0.1465 & 0.0592 & 0.2878 & 7 \\
\hline$A 9$ & 0.1122 & 0.0994 & 0.4698 & 5 \\
\hline
\end{tabular}

Summary of ranking results according to different multi-criteria decision-making methods are shown in Table 10.

The data in Table 10 revealed that:

- All five methods found that $A 3$ is the best option. In this case, $M R R=4160\left(\mathrm{~mm}^{3} / \mathrm{min}\right)$ is the maximum value among nine options performed. Although the surface roughness at A3 is not minimum, it is slightly higher than the surface roughness at $A 4, A 5$ and $A 7$. As a result, it can be said that $A 3$ is the best option. 
- The order of ranking options according to the three methods PIV, MOORA and TOPSIS is the same. This emphasizes that the ranking of options is successful and $A 3$ is really the best option.

- The EDAS and MARCOS method both identified $A 3$ as the best option (same as the three methods PIV, MOORA and TOPSIS). This also confirms that the application of the two methods EDAS and MARCOS has been successful in this study.

Table 10. Ranking options based on different methods.

\begin{tabular}{|c|c|c|c|c|c|c|c|}
\hline \multirow{2}{*}{ No. } & \multicolumn{2}{|c|}{ Criteria } & \multicolumn{5}{c|}{ Multi-criteria decision-making methods } \\
\cline { 2 - 8 } & $R a$ & $M R R$ & $E D A S$ & MARCOS & PIV & MOORA & TOPSIS \\
\hline$A 1$ & 0.571 & 1120 & 9 & 6 & 6 & 6 & 6 \\
\hline$A 2$ & 0.818 & 2400 & 6 & 7 & 8 & 8 & 8 \\
\hline$A 3$ & 0.493 & 4160 & 1 & 1 & 1 & 1 & 1 \\
\hline$A 4$ & 0.426 & 1680 & 4 & 4 & 4 & 4 & 4 \\
\hline$A 5$ & 0.470 & 3200 & 2 & 2 & 2 & 2 & 2 \\
\hline$A 6$ & 0.851 & 2080 & 8 & 9 & 9 & 9 & 9 \\
\hline$A 7$ & 0.437 & 2240 & 3 & 3 & 3 & 3 & 3 \\
\hline$A 8$ & 0.694 & 1600 & 7 & 8 & 7 & 7 & 7 \\
\hline$A 9$ & 0.717 & 3120 & 5 & 5 & 5 & 5 & 5 \\
\hline
\end{tabular}

- Five out of nine options ranked in the EDAS are the same as the three methods $P I V$, MOORA and TOPSIS. Meanwhile, seven out of nine options ranked in the MARCOS are the same as the three methods PIV, MOORA and TOPSIS. Between the two methods EDAS and $M A R C O S$, five out of nine options ranked are the same. In order to explain the difference in ranking the options, more in-depth studies in the field of mathematics are needed.

- Both the best and worst options defined by the MARCOS method are the same as the three methods PIV, MOORA and COPRAS. This is explained by the fact that the MARCOS method itself takes into account the ideal solution $(A I)$ and the opposite solution to the ideal solution $(A A I)$.

- To obtain the "minimum" surface roughness and the "maximum" MRR, the values of the spindle speed, feed rate and depth of cut are $788(\mathrm{rev} / \mathrm{min}), 70(\mathrm{~mm} / \mathrm{min})$ and $0.6(\mathrm{~mm})$, respectively.

\section{CONCLUSION}

In this research, the B410 steel milling experiment was conducted according to the matrix designed by the Taguchi method. The spindle speed, feed rate and depth of cut were the input parameters. The surface roughness and $M R R$ were identified in each experiment. Five methods EDAS, MARCOS, PIV, MOORA and TOPSIS were used for multi-criteria decision making so as to have the minimum surface roughness and maximum $M R R$ at the same time. Some conclusions are drawn as follows: 
- The ranking results of the options based on the three methods PIV, MOORA and TOPSIS are the same.

- All five multi-criteria decision-making methods identify an option that is considered the best among the implemented options.

- For the first time, two methods EDAS and MARCOS are used for multi-criteria decisionmaking in the milling process and successful in this study.

- Upon machining with a spindle speed of 788 (rev/min), a feed rate of $70(\mathrm{~mm} / \mathrm{min})$ and a depth of cut of 0.6 (mm), the surface roughness is and the $M R R$ is maximum.

\section{REFERENCES}

[1] Dich, T. V., Binh, N. T., Dat, N. T., Tiep, N. V., Viet, T. X. "Manufacturing technology", Science and Technics Publishing House, Ha Noi, 2003. (in Vietnamese).

[2] Manoj, M.,Gopal, A., Swati, D. C., Umesh, B., Veerendra, P. "Effect of Machine Feed Rate on Kerf-Width, Material Removal Rate, and Surface Roughness in Machining of $\mathrm{Al} / \mathrm{SiC}$ Composite Material with Wire Electrical Discharge Machine', Strojnícky časopis - Journal of mechanical engineering 70(1), pp. 81 - 88, 2020. DOI: 10.2478/scjme-2020-0008

[3] Huang, Y., Wang, L., Liang, S. Y. "Handbook of Manufacturing, World Scientific Publishing", 2019. DOI: 10.1142/11006

[4] Nguyen, V. C., Nguyen, T. D., Tien, D. H. "Cutting Parameter Optimization in Finishing Milling of Ti-6Al-4V Titanium Alloy under MQL Condition using TOPSIS and ANOVA Analysis, Engineering", Technology \& Applied Science Research 11(1), pp. 6775 - 6780, 2021. DOI: $10.48084 /$ etasr.4015

[5] Khanh, N. L., Cuong, N. V. "Parameter Selection to Ensure Multi-Criteria Optimization of the Taguchi Method Combined with the Data Envelopment Analysis-based Ranking Method when Milling SCM440 Steel", Engineering, Technology \& Applied Science Research 11(5), pp. 7551 - 7557, 2021. DOI: 10.48084/etasr.4315

[6] Anh, H. L. H., Tuan, T. K., Quang, N. H., Luan, N. H., Truong, T. M., Dung N. T. Q. "Optimization of Milling Process by Taguchi-PSI Method", E3S Web of Conferences 309 (01019), pp. 1 - 5, 2021. DOI: $10.1051 /$ e3sconf/202130

[7] Trung, D. D. "Multi-objective optimization of SKD11 steel milling process by Reference Ideal Method", International journal of geology 15, pp. 1 - 16, 2021. DOI: 10.46300/9105.2021.15.1

[8] Ghorabaee, M. K., Zavadskas, E. K., Olfat, L., Turskis, Z. "Multi-Criteria Inventory Classification Using a New Method of Evaluation Based on Distance from Average Solution (EDAS)", Informatica 26 (3), pp. $435-451,2015$. DOI: 10.15388/Informatica.2015.57

[9] Yalcin, N., Uncu, N. "Applying EDAS as an applicable MCDM method for industrial robot selection", Sigma Journal of Engineering and Natural Sciences 37 (3), pp. 779 796, 2019.

[10] Tabasam R., Asif A., Yu-Ming C. "Hybrid BW-EDAS MCDM methodology for optimal industrial robot selection", Plos one 16 (2), pp. 1 - 18, 2021. DOI: 10.1371/journal.pone.0246738 
[11] Mathew, M., Sahu, S. "Comparison of new multi-criteria decision making methods for material handling equipment selection”, Management Science Letters 8, pp. 139 - 150, 2018. DOI: $10.5267 /$ j.msl.2018.1.004

[12] Siqi, Z., Hui, G., Guiwu, W., Yu, W., Cun, W. "Evaluation Based on Distance from Average Solution Method for Multiple Criteria Group Decision Making under Picture 2-Tuple Linguistic Environment", Mathematics 7 (243), pp. 1 - 14, 2019. DOI: 10.3390/math7030243

[13] Aggarwal, A., Choudhary, C., Mehrotra, D. "Evaluation of smartphones in Indian market using EDAS", Procedia Computer Science 132, pp. 236 - 243, 2018. DOI: 10.1016/j.procs.2018.05.193

[14] Shaaban, S. M., Abd, E. A. M. "Integration of Evaluation Distance from Average Solution Approach with Information Entropy Weight for Diesel Engine Parameter Optimization", International Journal of Intelligent Engineering and Systems 13 (3), pp. 101 - 111, 2020. DOI: $10.22266 /$ ijies2020.0630.10

[15] Chairman, C. A., Ravichandran, M., Mohanavel, V., Sathish, T., Rashedi, A., Alarifi, I. M., Badruddin, I. A., Anqi, A. E., Afzal, A. "Mechanical and Abrasive Wear Performance of Titanium Di-Oxide Filled Woven Glass Fibre Reinforced Polymer Composites by Using Taguchi and EDAS Approach", Materials 14 (5257), pp. 1 - 18, 2021. DOI: $10.3390 / \mathrm{ma} 14185257$

[16] Almulhim, T. S. "Multi-Criteria evaluation of insurance industries performance: an analysis of EDAS based on the entropy weight", International Journal for Quality Research 14 (4), pp. 1097 -1114, 2019. DOI: 10.24874/IJQR14.04-07

[17] Krishankumar, R., Pamucar, D., Deveci, M., Ravichandran, K. S. "Prioritization of zero-carbon measures for sustainable urban mobility using integrated double hierarchy decision framework and EDAS approach", Science of the Total Environment 797 (149068), pp. 1 - 12, 2021. DOI: 10.1016/j.scitotenv.2021.149068

[18] Shihui, L., Bo, W. "Research on Evaluating Algorithms for the Service Quality of Wireless Sensor Networks Based on Interval-Valued Intuitionistic Fuzzy EDAS and CRITIC Methods", Mathematical Problems in Engineering, 2020, pp. 1 - 12, 2020. DOI: $10.1155 / 2020 / 5391940$

[19] Uluta, A., "Sewing Machine Selection for a Textile Workshop by Using EDAS Method", Journal of business research - Turk 9 (2), pp. 169 - 183, 2017.

[20] Stevic, Z., Pamucar, D., Puska, A., Chatterjee, P. "Sustainable supplier selection in healthcare industries using a new MCDM method: Measurement Alternatives and Ranking according to COmpromise Solution (MARCOS)", Computers \& Industrial Engineering, 140, pp. 1 - 33, 2020. DOI: 10.1016/j.cie.2019.106231

[21] Tadic S., Kilibarda M., Kovac M., Zecevic S. "The assessment of intermodal transport in countries of the Danube region", International Journal for Traffic and Transport Engineering 11 (3), pp. 375 - 391, 2021. DOI: 10.7708/ijtte2021.11(3).03

[22] Miomir, S., Zeljko, S., Kumar, D. D., Marko, S., Dragan, P. “A New Fuzzy MARCOS Method for Road Traffic Risk Analysis”, Mathematics 8 (457), pp. 1 - 17, 2020. DOI: 10.3390/math8030457

[23] Ulutas, A., Karabasevic, D., Popovic, G., Stanujkic, D., Nguyen, P. T., Karakoy C. "Development of a Novel Integrated CCSD-ITARA-MARCOS Decision-Making 
Approach for Stackers Selection in a Logistics System”, Mathematics 8 (1672), pp. 1 15, 2020. DOI: $10.3390 /$ math 8101672

[24] Stevic, Z., Brkovic, N. "A Novel Integrated FUCOM-MARCOS Model for Evaluation of Human Resources in a Transport Company", Logistics 4 (4), pp. 1 - 15, 2020. DOI: 10.3390/logistics4010004

[25] Anysz, H., Nicał, A., Stevic, Z., Grzegorzewski, M., Sikora, K. "Pareto Optimal Decisions in Multi-Criteria Decision Making Explained with Construction Cost Cases", Symmetry 13 (46), pp. 1 - 2 5, 2021. DOI: 10.3390/sym13010046

[26] Yakup, C., Fatih, T. "An in-depth review of theory of the TOPSIS method: An experimental analysis", Journal of Management Analytics 7 (2), pp. 1 - 21, 2020. DOI: $10.1080 / 23270012.2020 .1748528$

[27] Trung, D. D. "A combination method for multi-criteria decision making problem in turning process", Manufacturing Review 8 (26), pp. 1 - 17, 2021. DOI: $10.1051 / \mathrm{mfreview} / 2021024$

[28] Himadri, M., Abhijit, S. "Application of MCDM based hybrid optimization tool during turning of ASTM A588", Decision Science Letters 7, pp. 143 - 156, 2018. DOI: $10.5267 / \mathrm{j} . \mathrm{dsl} .2017 .6 .003$

[29] Trung, D. D. "Appliation of Topsis and PIV method for multi-criteria decision making in hard turning process", Journal of Machine Engineering 21 (4), pp. 1 - 15, 2021. DOI: $10.36897 / \mathrm{jme} / 142599$

[30] Mufazzal, S., Muzakkir, S. M. "A New Multi-Criterion Decision Making (MCDM) Method Based on Proximity Indexed Value for Minimizing Rank Reversals", Computers \& Industrial Engineering 119, pp. $427-438$, 2018. DOI: 10.1016/j.cie.2018.03.045

[31] Brauers, W. "Optimization methods for a stakeholder society. A revolution in economic thinking by multi-objective optimization", Publisher: springer before Kluwer, 2004. DOI: $10.1007 / 978-1-4419-9178-2$

[32] Hwang, C. L., Lai, Y. J., Liu, T. Y. "A new approach for multiple objective decision making", Computers \& Operations Research 20 (8) pp. 889 - 899, 1993. DOI: 10.1016/0305-0548(93)90109-V

[33] Tadeusz, D. B. R., Edward, Z. B., Allan, N. G., Leslie, R. H., Wyatt, M. "16Manufacturing methods, Mechanical Engineer's Reference Book (Twelfth Edition)", 16-3 (16-112), pp. 16 - 21, 1994. DOI: 10.1016/B978-0-7506-1195-4.50020-8

[34] Trung, D. D. "Influence of Cutting Parameters on Surface Roughness during Milling AISI 1045 Steel", Tribology in Industry, 42(4), pp. 658 - 665, 2020. DOI: 10.24874/ti.969.09.20.11

[35] Phadke, M. S. “Quality Engineering Using Robust Design”, Printice Hall, 1989.

[36] Himanshu, P. R., Lalta, P., Mayank, P., Vineet, T. “An estimating the effect of process parameters on matel removal rate and surface roughness in WEDM of composite AL6063/SIC/Al $\mathrm{O}_{3} \mathrm{O}_{3}$ by Taguchi method", Strojnícky časopis - Journal of mechanical engineering 67 (2), pp. 25 - 36, 2017. DOI: 10.1515/scjme-2017-0015 
[37] Hieu, T. T., Thao, N. X., Thuy, L. T. M. "Application of MOORA and COPRAS Models to Select Materials for Mushroom Cultivation", Vietnam Journal of Agricultural Sciences 17 (4), pp. 322 - 331, 2019. (in Vietnamese). 